\title{
Methyl 9-(2-(2,5-Dihydro-5-pentylfuryl))-nonanoate in the Copper-catalyzed Decomposition Products of Methyl Linoleate Hydroperoxides and Some Other Products
}

\author{
Masako ToKITA and Makio Morita \\ Department of Food and Nutrition, Japan Women's University, \\ 2-8-1, Mejirodai, Bunkyo-ku, Tokyo 112, Japan \\ Received June 2, 1986
}

\begin{abstract}
The hydroperoxide of methyl linoleate containing 95\% 13-hydroperoxide and 5\% 9-hydroperoxide was decomposed in benzene with $10^{-4} \mathrm{M}$ cupric naphthenate at $75 \sim 80^{\circ} \mathrm{C}$ under degassed conditions. The decomposition products were fractionated by Sephadex LH-20 column chromatography with chloroform-hexane $(2: 1, \mathrm{v} / \mathrm{v})$ and the fractions were purified by HPLC. In addition to the known products, three compounds were identified as methyl 9-(2-(2,5-dihydro-5pentylfuryl))-nonanoate, methyl 8-(2-furyl)-octanoate, and methyl 9(13)-hydroperoxy-12,13$(9,10)$-epoxy-10(12)-octadecenoate as miner decomposition products by MS and IR spectrophotometry.
\end{abstract}

Transition metal ions have dual effects on the decomposition of hydroperoxide. ${ }^{1)}$ In the lower valence state, they reduce hydroperoxide to $\mathrm{RO}$ - and in the higher valence state, oxidize it to ROO $\cdot$. However in the case of copper, it seems unlikely that the reaction of $\mathrm{Cu}^{2+}+\mathrm{ROOH} \rightarrow \mathrm{Cu}^{+}+\mathrm{ROO} \cdot+\mathrm{H}^{+}$(1) occurs because $\mathrm{Cu}^{2+}$ is stable and its oxidizing power is low. O'Brien reported that $\mathrm{Cu}^{2+}$ was more effective than $\mathrm{Cu}^{+}$for the decomposition of hydroperoxide of linoleate ${ }^{2)}$. Therefore, some mechanism other than reaction 1 by which $\mathrm{Cu}^{2+}$ acts on the hydroperoxide is necessary, but what it is isn't clear. Elucidation of the products of copper-catalyzed decomposition will give a clue.

Schieberle et al. identified the decomposition products of 13-hydroperoxide of linoleate arising from the system catalyzed by copper(II) palmitate ${ }^{3)}$. They reported oxooctadecadienoate, oxoepoxyoctadecenoate, hydroxyoctadecadienoate, hydroxyepoxyoctadecenoate, and dioctadecadienoate peroxides as the decomposition products in an atmosphere of nitrogen. In our laboratory, 13-hydroperoxide of linoleate was decomposed by cupric naph- thenate under degassed conditions and 8phenyloctanoate and a carbon-carbon linked dimer were identified. ${ }^{4)}$ In this paper, a novel product of methyl 9-(2-(2,5-dihydro-5-pentylfuryl))-nonanoate (compound I), and two compound of methyl 8-(2-furyl)-octanoate (compound II) and methyl 9(13)-hydroperoxy-12,13(9,10)-e p oxy - 10 - (12)octadecenoate (compounds III) are reported.

\section{MATERIALS AND METHODS}

Materials. Hydroperoxide of methyl linoleate containing 95\% 13-hydroperoxide and 5\% 9-hydroperoxide was prepared by lipoxygenase oxidation as described by Hamberg et al. ${ }^{5)}$ The hydroperoxide was purified by Sephadex LH-20 column chromatography and thin layer chromatography as previously described. ${ }^{6}$ )

Decomposition of the hydroperoxide. The purified hydroperoxide ( $300 \mathrm{mg}$ ) was decomposed in benzene solution of cupric naphthenate $\left(10^{-4} \mathrm{M}, 50 \mathrm{ml}\right)$ under degassed conditions at $75 \sim 80^{\circ} \mathrm{C}$ overnight.

Sephadex LH-20 column chromatography. Decomposition products were fractionated by Sephadex LH-20 column chromatography. The column was $1.5 \times 72 \mathrm{~cm}$ and the products were eluted with chloroform-hexane $(2: 1$, 
$\mathrm{v} / \mathrm{v})$. The fractions eluted in elution volume of $30 \sim 50 \mathrm{ml}$ (A) and $100 \sim 150 \mathrm{ml}$ (B) were collected. Fraction A contained low polar compounds (A-1), oxo compound, and dimers. Fraction B contained an $N, N^{\prime}-p$-phenylenediamine sensitive product (B-1) which had a peroxy group but was much more polar than intact hydroperoxide. Fraction A was put on a silica gel column and eluted stepwise with hexane-ether $(97: 3$ and $95: 5, \mathrm{v} / \mathrm{v})$ to collect fraction A-1. Fraction B was purified on a silica gel column by stepwise elution of hexane-ether $(95: 5,90: 10,85: 5$, $80: 20$, and $60: 40, \mathrm{v} / \mathrm{v})$. Fraction B-1 was eluted with hexane-ether $(3: 2, \mathrm{v} / \mathrm{v})$ after intact hydroperoxide was eluted.

HPLC. Each fraction was injected into a liquid chromatograph (Shimadzu LC-3A) on a Zorbax SIL column $(0.46 \times 15 \mathrm{~cm}$, DuPont $)$. Compounds I and II were isolated from fraction A-1. The eluent was 3\% ether in hexane and the flow rate was $1.5 \mathrm{ml} / \mathrm{min}$. A refractive index detector (Shimadzu RID-2A) was used. Compounds III were isolated from fraction B-1 with hexane-ether $(4: 1, \mathrm{v} / \mathrm{v})$. The flow rate was $2.9 \mathrm{ml} / \mathrm{min}$ and the refractive index detector was used. Compounds III consisted of four peak materials.

$G L C$. Compound I isolated by HPLC was further purified by GLC. The conditions of GLC were the same as previously reported ${ }^{6)}$ except that the oven temperature was programmed from 100 to $270^{\circ} \mathrm{C}$ at a rate of $8^{\circ} \mathrm{C} / \mathrm{min}$.

Spectrophotometry. Mass spectra were obtained with a mass spectrometer (JEOL JMS DX-300). The GC columns were $3 \mathrm{~mm} \times 2 \mathrm{~m}$ and $3 \mathrm{~mm} \times 1 \mathrm{~m}$ glass columns packed with $3 \%$ Silar $10 \mathrm{C}$ on Diasolid L-1. The temperature was elevated from 100 to $270^{\circ} \mathrm{C}$ at a rate of $8^{\circ} \mathrm{C} / \mathrm{min}$. The ionization potentials were $70 \mathrm{eV}$ for EI method and $300 \mathrm{eV}$ for CI. The reaction gas of CI was isobutane. IR spectra were obtained with a Hitachi 285 spectrophotometer.

Synthesis of compound I (methyl 9-(2-(2,5-dihydro-5pentylfuryl))-nonanoate). cis-2-Butene-1,4-diol (15g) was allowed to react with triphenylchloromethane $(123 \mathrm{~g})$ in dehydrated pyridine to prepare 4-triphenylmethoxy-2buten-1-ol. 4-Triphenylmethoxy-2-buten-1-ol was oxidized with $\mathrm{MnO}_{2}{ }^{7)}$ in hexane. 4-Triphenylmethoxy-2butenal was produced, and it was purified by column chromatography on silica gel with hexane-ether $(9: 1, \mathrm{v} / \mathrm{v})$, with a yield of $1.91 \mathrm{~g} . R f=0.34$ (silica gel $\mathrm{GF}_{254}$, hexaneether, 2:1). A Grignard reagent was prepared by the reaction of 1-bromopentane $(1.1 \mathrm{ml})$ with $\mathrm{Mg}(0.24 \mathrm{~g})$ in anhydrous ether with refluxing. The reagent was allowed to react with 4-triphenylmethoxy-2-butenal $(0.99 \mathrm{~g})$. Produced 1-triphenylmethoxy-2-nonen-4-ol was purified by column chromatography on silica gel with hexaneether $(90: 10$ and $85: 5, \mathrm{v} / \mathrm{v})$ with a yield of $1.04 \mathrm{~g}$ and an
$R f=0.28$ (hexane-ether, $2: 1, \mathrm{v} / \mathrm{v}$ ). 1-triphenylmethoxy-2nonen-4-ol $(0.99 \mathrm{~g})$ was acetylated with acetic anhydridepyridine $(1: 2, \mathrm{v} / \mathrm{v})$ with a yield of $1.03 \mathrm{~g}$ and an $R f=0.59$ (hexane-ether, 2:1, v/v). 4-Acetoxy-1-triphenylmethoxy2-nonene $(1.00 \mathrm{~g})$ was hydrolyzed with $0.01 \mathrm{~N} \mathrm{HCl}$ in acetone-water $(9: 1, \mathrm{v} / \mathrm{v})$ with refluxing. The 4-acetoxy-2nonen-1-ol produced was purified by column chromatography on silica gel with hexane-ether $(80: 20,70: 30$ and $60: 40, \mathrm{v} / \mathrm{v}$ ) with a yield of $0.34 \mathrm{~g}$ and an $R f=0.08$ (hexaneether, 2:1, v/v). MS (TMS derivative) $m / z: 242,213$ $\left(\mathrm{M}-\mathrm{CH}_{3} \mathrm{COO}\right), 117$ and 73. 4-Acetoxy-2-nonen-1-ol $(0.33 \mathrm{~g})$ was oxidized with $\mathrm{MnO}_{2}(1.2 \mathrm{~g})$ in hexane. 4Acetoxy-2-nonenal was produced with a yield of $0.18 \mathrm{~g}$ and an $R f=0.28$ (hexane-ether, $2: 1, \mathrm{v} / \mathrm{v}$ ).

Nonane-1,9-diol was brominated by refluxing with $\mathrm{HBr}$ (1.5 fold the molar quantity of the diol) for $1 \mathrm{hr}$. 9Bromononan-1-ol was purified on a silica gel column with hexane-ether $(60: 40$ and $50: 50, \mathrm{v} / \mathrm{v})$. 9-Bromononan-1-ol $(4.2 \mathrm{~g})$ was allowed to react with triphenylchloromethane $(6.6 \mathrm{~g})$ in dehydrated pyridine, producing 1-bromo-9triphenylmethoxynonane that was purified on a silica gel column with hexane with a yield of $3.8 \mathrm{~g}$ and an $R f=$ 0.62 (hexane-ether, 2:1, v/v). A Grignard reagent was prepared by the reaction of 1-bromo-9-triphenylmethoxynonane $(3.7 \mathrm{~g})$ with $\mathrm{Mg}(0.2 \mathrm{~g})$ in anhydrous ether and the reagent was allowed to react with 4acetoxy-2-nonenal $(0.18 \mathrm{~g})$ in ether. Produced 18triphenylmethoxy-7-octadecene-6,9-diol was purified on a silica gel column with hexane-ether $(3: 2,1: 1,1: 2, \mathrm{v} / \mathrm{v})$ and ether with a yield of $0.38 \mathrm{~g}$ and $R f=0.35$ and 0.23 (ether). 18-Triphenylmethoxy-7-octadecene-6,9-diol $(0.37 \mathrm{~g})$ was acetylated with acetic anhydride-pyridine $(1: 2, \mathrm{v} / \mathrm{v})$ with a yield of $0.37 \mathrm{~g}$ and an $R f=0.61$ (hexaneether, $2: 1, \mathrm{v} / \mathrm{v}$ ). 6,9-Diacetoxy-18-triphenylmethoxy-7octadecene $(0.45 \mathrm{~g})$ was hydrolyzed by $0.01 \mathrm{~N} \mathrm{H}_{2} \mathrm{SO}_{4}$ in acetone-water $(9: 1)$ with refluxing. $R f=0.09$ (hexaneether, $2: 1, \mathrm{v} / \mathrm{v})$. The reaction mixture was cooled in an icewater bath and a reagent $(0.2 \mathrm{ml})$ containing $\mathrm{CrO}_{3}(2.67 \mathrm{~g})$ and $\mathrm{H}_{2} \mathrm{SO}_{4}(2.3 \mathrm{ml})$ in $10 \mathrm{ml}$ water was added to the reaction mixture with stirring, producing 10,13-diacetoxy11-octadecenoic acid which was purified on a silica gel column with hexane-ether $(90: 10,80: 20,60: 40,50: 50$, $\mathrm{v} / \mathrm{v}$ ) and ether with a yield of $0.88 \mathrm{~g}$ and an $R f=0.27$ (hexane-ether-acetic acid, 1:1:0.02, v/v). MS (methyl ester) $m / z: 353\left(\mathrm{M}-\mathrm{CH}_{3} \mathrm{COO}\right), 310$, and 169. 10, 13Diacetoxy-11-octadecenoic acid $(0.08 \mathrm{~g})$ was saponified with $2 \mathrm{~N} \mathrm{KOH}$ in methanol. $R f=0.30$ and $0.22(1 \%$ acetic acid in ether), producing 10,13-dihydroxy-11-octadecenoic acid $(0.06 \mathrm{~g})$ which was methylated with diazomethane. $R f=0.42$ and 0.24 (ether). MS (TMS derivative) $\mathrm{m} / \mathrm{z}: 457$ $\left(\mathrm{M}-\mathrm{CH}_{3}\right), 441\left(\mathrm{M}-\mathrm{OCH}_{3}\right), 401,301,273$ and 173. Methyl-10, 13-dihydroxy-11-octadecenoate was dissolved in $2 \sim 3 \mathrm{ml}$ of 1 -butanol and $1 \mathrm{ml}$ of water containing $100 \mathrm{mg} \mathrm{HgO}$ and $10 \mathrm{mg} \mathrm{HNO}_{3}$ was added to the butanol solution with refluxing ${ }^{8}$. The 2,5-dihydrofuran derivative produced was purified on a silica gel column with hexaneether $(95: 5, \mathrm{v} / \mathrm{v})$. MS $m / z: 310\left(\mathrm{M}^{+}\right), 297\left(\mathrm{M}-\mathrm{OCH}_{3}\right)$, 
239, 207, and 139.

\section{RESULTS}

\section{Compounds I and II}

Fraction A-1 was subjected to HPLC on a Zorbax SIL column and the fractions containing compounds I and II were isolated (Fig. 1). The other peak materials (a, b, and c) shown in Fig. 1 were identified by GC-MS as methyl 13-oxotridecadienoate, methyl oxooctadecadienoate, and 2,4-decadienal, respectively by comparing their mass spectra with those of library data. After purification by GLC $\left(t_{R}=13.5 \mathrm{~min}\right)$, compound I was injected into a mass spectrometer. Retention time on Silar

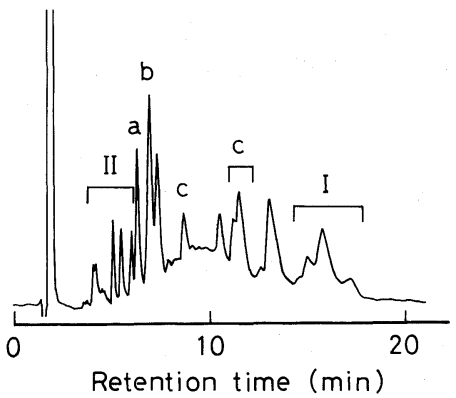

FIG. 1. High Performance Liquid Chromatogram of Fraction A-1.

I, methyl 9-(2-(2,5-dihydro-5-pentylfuryl))-nonanoate (compound I); II, methyl 8-(2-furyl)-octanoate (compound II); a, methyl 13-oxotridecadienoate; b, methyl oxooctadecadienoate; c, 2,4-decadienal.

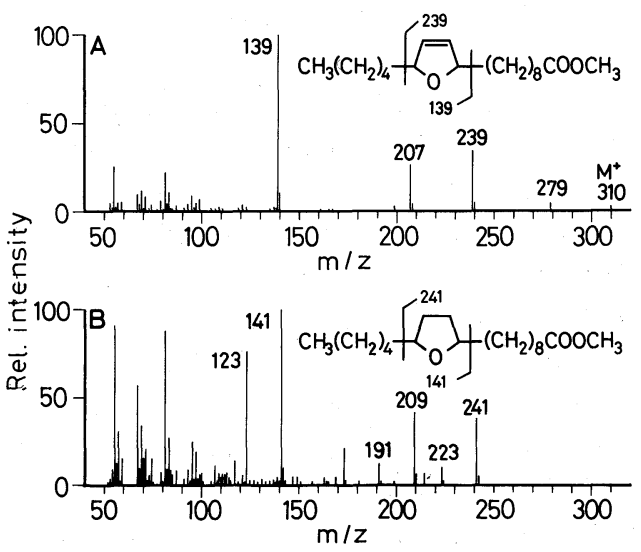

$10 \mathrm{C}(1 \mathrm{~m})$ of compound I was about $12 \mathrm{~min}$. Figure $2 \mathrm{~A}$ shows the EI mass spectrum of compound I. Fragment ions of $m / z: 310\left(\mathrm{M}^{+}\right)$, $279\left(\mathrm{M}-\mathrm{OCH}_{3}\right), 239\left(\mathrm{M}-\mathrm{CH}_{3}\left(\mathrm{CH}_{2}\right)_{4}\right), 207$ $\left(239-\mathrm{CH}_{3} \mathrm{OH}\right)$ and $139\left(\mathrm{M}-\left(\mathrm{CH}_{2}\right)_{8} \mathrm{COO}-\right.$ $\mathrm{CH}_{3}$ ) were shown. The $\mathrm{CI}$ mass spectrum showed intense $\mathrm{M}+1$ ion of $\mathrm{m} / \mathrm{z}: 311$. Elemental compositions found by high resolution MS were as follows: $m / z: 310.25376$ $\left(\mathrm{C}_{19} \mathrm{H}_{34} \mathrm{O}_{3}\right), 279.23120\left(\mathrm{C}_{18} \mathrm{H}_{31} \mathrm{O}_{2}\right), 239.16711$ $\left(\mathrm{C}_{14} \mathrm{H}_{23} \mathrm{O}_{3}\right), \quad 207.14008 \quad\left(\mathrm{C}_{13} \mathrm{H}_{19} \mathrm{O}_{2}\right)$ and $139.11282\left(\mathrm{C}_{9} \mathrm{H}_{15} \mathrm{O}\right)$. A structure for compound I was postulated as shown in Fig. 2A from these MS results. After hydrogenation catalyzed by Pd black, the EI mass spectrum showed intense ions of $\mathrm{m} / \mathrm{z}: 241$ $\left(\mathrm{M}-\mathrm{CH}_{3}\left(\mathrm{CH}_{2}\right)_{4}\right), \quad 223 \quad\left(241-\mathrm{H}_{2} \mathrm{O}\right), \quad 209$ $\left(241-\mathrm{CH}_{3} \mathrm{OH}\right), 141\left(\mathrm{M}-\left(\mathrm{CH}_{2}\right)_{8} \mathrm{COOCH}_{3}\right)$, and $123\left(141-\mathrm{H}_{2} \mathrm{O}\right)$ as shown in Fig. 2B. Though the molecular ion $(\mathrm{m} / z: 312)$ couldn't be detected, these results suggested that the hydrogenated compound I was 9-(2(tetrahydro-5-pentylfuryl))-nonanoate. Since compound I was a minor product and a sufficient amount for IR or NMR spectrophotometry could not be obtained, 9-(2-(2,5dihydro-5-pentylfuryl))-nonanoate was synthesized to confirm the structure of compound I. Retention time of $\mathrm{GC}$ and the EI mass spectrum of synthesized 9-(2-(2,5-dihydro-5pentylfuryl))-nonanoate agreed with those of compound I. Accordingly, compound I was identified as 9-(2-(2,5-dihydro-5-pentylfuryl))nonanoate.

Retention time of compound II on Silar 10C (1m) was about $8.3 \mathrm{~min}$. The EI mass spectrum of compound II showed fragment ions nearly identical to those reported by Frankel et al. ${ }^{9)}$ for 8- (2-furyl) -octanoate; $m / z$ : $224\left(\mathrm{M}^{+}\right), 193$ $\left(\mathrm{M}-\mathrm{OCH}_{3}\right), 137\left(\mathrm{M}-\left(\mathrm{CH}_{2}\right)_{2} \mathrm{COOCH}_{3}\right), 123$ $\left(137-\mathrm{CH}_{2}\right), 95\left(123-\left(\mathrm{CH}_{2}\right)_{5} \mathrm{COOCH}_{3}\right)$, and $81\left(\mathrm{M}-\left(\mathrm{CH}_{2}\right)_{6} \mathrm{COOCH}_{3}\right)$. The CI mass spectrum showed an intense ion of $m / z: 225$ (M $+1)$. High resolution MS indicated $\mathrm{m} / z$ of $224.13800\left(\mathrm{C}_{13} \mathrm{H}_{20} \mathrm{O}_{3}\right), 95.04836\left(\mathrm{C}_{6} \mathrm{H}_{7} \mathrm{O}\right)$, and $81.03248\left(\mathrm{C}_{5} \mathrm{H}_{5} \mathrm{O}\right)$. The mass spectra and $\mathrm{GC}$ retention time of compound II agreed with those of the authentic sample, therefore it was 
confirmed that compound II was 8- (2-furyl)octanoate.

\section{Compounds III}

Fraction B-1 was an $N, N^{\prime}-p$-phenylenediamine sensitive material and separated into four peaks on HPLC (Fig. 3). Each peak material (compound III-1, III-2, III-3, or III-4) was isolated by HPLC and reduced to the corresponding hydroxy derivative with triphenylphosphine. The reduced products of compounds III were eluted much more slowly (14 17 min) than compounds III. They were converted into TMS derivatives and analyzed by GC-MS. The EI mass spectra of TMS derivatives of reduced compounds III-1, III2 , and III-4 were identical with those of 9-TMSO-12,13-epoxy-10-octadecenoate reported by Hamberg et al. ${ }^{10)} ; m / z: 398\left(\mathrm{M}^{+}\right)$,

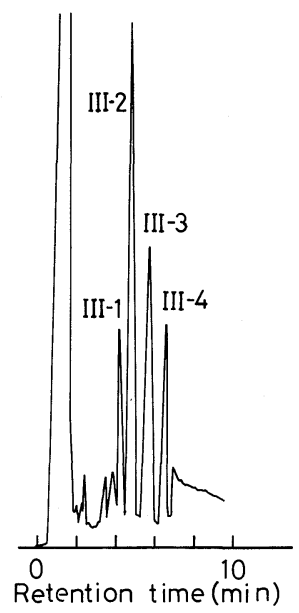

FIG. 3. High Performance Liquid Chromatogram of Fraction B-1. III-1, III-2 and III-4, methyl 9-hydroperoxy12,13-epoxy-10-octadecenoate; III-3, methyl 13-hydroperoxy-9, 10-epoxy-11-octadecenoate.

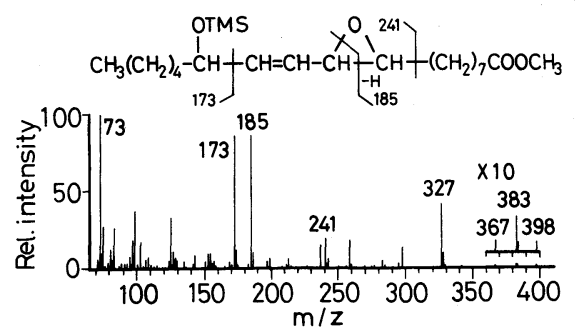

FIG. 4. Mass Spectrum (EI) of Compound III-3.
$383\left(\mathrm{M}-\mathrm{CH}_{3}\right), 367\left(\mathrm{M}-\mathrm{OCH}_{3}\right), 259(\mathrm{CHO}-$ $\left.\mathrm{TMS}\left(\mathrm{CH}_{2}\right)_{7} \mathrm{COOCH}_{3}\right), 241\left(\mathrm{M}-\left(\mathrm{CH}_{2}\right)_{7} \mathrm{COO}-\right.$ $\left.\mathrm{CH}_{3}\right)$, and $99\left(\mathrm{CH}_{3}\left(\mathrm{CH}_{2}\right)_{4} \mathrm{CO}\right)$. High resolution MS revealed: $398.28642\left(\mathrm{C}_{22} \mathrm{H}_{42} \mathrm{O}_{4} \mathrm{Si}\right)$, $383.26422\left(\mathrm{C}_{21} \mathrm{H}_{39} \mathrm{O}_{4} \mathrm{Si}\right), 259.17225\left(\mathrm{C}_{13} \mathrm{H}_{27^{-}}\right.$ $\left.\mathrm{O}_{3} \mathrm{Si}\right), 241.16295\left(\mathrm{C}_{13} \mathrm{H}_{25} \mathrm{O}_{2} \mathrm{Si}\right)$, and 99.08030 $\left(\mathrm{C}_{6} \mathrm{H}_{11} \mathrm{O}\right)$. The EI mass spectrum of the TMS derivative of reduced compound III-3 showed the fragment ions at $m / z: 398\left(\mathrm{M}^{+}\right), 383$ $\left(\mathrm{M}-\mathrm{CH}_{3}\right), 367\left(\mathrm{M}-\mathrm{OCH}_{3}\right), 327\left(\mathrm{M}-\mathrm{CH}_{3}-\right.$ $\left.\left(\mathrm{CH}_{2}\right)_{4}\right), \quad 241 \quad\left(\mathrm{M}-\left(\mathrm{CH}_{2}\right)_{7} \mathrm{COOCH}_{3}\right), \quad 185$ $\left(\mathrm{CO}\left(\mathrm{CH}_{2}\right)_{7} \mathrm{COOCH}_{3}\right)$, and $173\left(\mathrm{CH}_{3}\left(\mathrm{CH}_{2}\right)_{4}{ }^{-}\right.$ CHOTMS) as shown in Fig. 4. High resolution MS revealed: $383.25926\left(\mathrm{C}_{21} \mathrm{H}_{39} \mathrm{O}_{4} \mathrm{Si}\right)$, $327.19800\left(\mathrm{C}_{17} \mathrm{H}_{31} \mathrm{O}_{4} \mathrm{Si}\right), 241.16333\left(\mathrm{C}_{13} \mathrm{H}_{25}\right.$ $\left.\mathrm{O}_{2} \mathrm{Si}\right), 185.11617\left(\mathrm{C}_{10} \mathrm{H}_{17} \mathrm{O}_{3}\right)$, and 173.13575 $\left(\mathrm{C}_{9} \mathrm{H}_{21} \mathrm{OSi}\right)$. These MS results suggested that the reduced product of compound III-3 was 13-hydroxy-9,10-epoxy-11-octadecenoate. The IR spectrum of compounds III showed characteristic absorptions of trans epoxide at $880 \mathrm{~cm}^{-1}$, trans double bond at 960 $\mathrm{cm}^{-1}$, hydroxyl at $3450 \mathrm{~cm}^{-1}$, and ester carbonyl at $1740 \sim 1730 \mathrm{~cm}^{-1}$, which agreed with those of 13-hydroxy-9,10-epoxy-11-octadecenoate reported by Schieberle et al. ${ }^{11}$ and Neff et al. ${ }^{12)}$. These MS and IR results suggested that compounds III-1, III-2, and III-4 were 9-hydroperoxy-12,13-epoxy-10octadecenoate and compound III-3 was 13hydroperoxy-9,10-epoxy-11-octadecenoate.

\section{DISCUSSION}

Compound $\mathrm{I}$ is a novel product which has not been reported as a decomposition product of the hydroperoxide of linoleate. Though the mechanism of its formation is not clear, it seemed that the hydroperoxy group at carbon 13 underwent cyclization via RO.

Compound II was reported as a thermal decomposition product of 6-membered hydroperoxy epidioxide ${ }^{13}$ and hydroperoxyepoxyoctadecenoate $^{14)}$ (compounds III) which were secondary oxidation products of the hydroperoxide. Parson suggested ${ }^{15)}$ a mechanism of formation of pentylfuran from the 9-hydroperoxide; the hydroperoxide de- 
composed into a conjugated diene radical which was oxidized to vinyl hydroperoxide, and it cyclized. The formation of compound II would be explained by application of this mechanism to 13-hydroperoxide. However compound II has not been reported as a thermal decomposition product of the hydroperoxide of linoleate ${ }^{16)}$.

Compounds III were reported as a decomposition product of the 13-hydroperoxide allowed to react with a soybean extract or cysteine- $\mathrm{FeCl}_{3}$ in an atmosphere of oxygen. ${ }^{17)}$ A mechanism of its formation was proposed; the $\mathrm{RO}$-produced by decomposition of the hydroperoxide cyclized to $\alpha$-unsaturation, and oxygen combined with produced epoxy radicals. ${ }^{17)}$ Evidently participation of oxygen is necessary to this mechanism. In our experiment, the hydroperoxide was decomposed under degassed conditions, so that the production of compounds III suggested that oxygen was generated in the process of the decomposition. Unpublished data of an other study indicated the generation of oxygen. Among the decomposition products, carbon-carbon linked dimer which we previously reported ${ }^{4)}$ was most abundant and occupied about $10 \%$ of all the products. Since this dimer lacks oxygen in comparison with the hydroperoxide, the generation of oxygen is expected to be accompanied by its production. There is another unpublished datum indicating the yield of the dimer tended to increase when the hydroperoxide was decomposed with a higher concentration of $\mathrm{Cu}^{2+}$. Thus, the mechanistic relation of the production of the dimer and oxygen to reduction of $\mathrm{Cu}^{2+}$ to $\mathrm{Cu}^{+}$is an interesting problem. The detailed study on this problem is in progress.

Acknowledgment. We wish to thank Misses Yoshiko Higashi, Mariko Suzuki, Mariko Abe, and Saori Kumeuchi for technical assistance.

\section{REFERENCES}

1) K. U. Ingold, "Symposium on Foods: Lipids and Their Oxidation," ed. by H. W. Schultz, Avi Publishing Co., Westport, Conn., 1962, pp. $93 \sim 121$.

2) P. J. O'Brien, Can. J. Biochem., 47, 485 (1969).

3) P. Schieberle and W. Grosch, Z. Lebensm. Unters. Forsch., 173, 192 (1981).

4) M. Morita and M. Tokita, Agric. Biol. Chem., 48, 2567 (1984).

5) M. Hamberg, Anal. Biochem., 43,515 (1971).

6) M. Tokita and M. Morita, Agric. Biol. Chem., 49, 3545 (1985).

7) J. Attenburrow, A. F. B. Cameron, J. H. Chapman, R. M. Evans, A. Hems, A. B. A. Jansen and T. Walker, J. Chem. Soc., 1952, 1094.

8) R. F. Drury, U. S. Patent, 4231941 (1980) [C.A., 94, 139605 (1980)].

9) E. N. Frankel, W. E. Neff and E. Selke, Lipids, 18, 353 (1983).

10) M. Hamberg, Lipids, 10, 87 (1975).

11) P. Schieberle, B. Tsoukalas and W. Grosch, Z. Lebensm. Unters. Forsch., 168, 448 (1979).

12) W. E. Neff, E. N. Frankel, C. R. Scholfield and D. Weisleder, Lipids, 13, 415 (1978).

13) W. E. Neff, E. N. Frankel, E. Selke and D. Weisleder, Lepids, 18, 868 (1983).

14) H. W. Gardner and E. Selke, Lipids, 19, 375 (1984).

15) A. M. Parsons, Abstracts of Papers, Third International Symposium on Metal-Catalyzed Lipid Oxidation, Institut Crops Gras, Paris, 1973, p. 148.

16) E. N. Frankel, W. E. Neff and E. Selke, Lipids, 16, 279 (1981)

17) H. W. Gardner, D. Weisleder and R. Kleiman, Lipids, 13, 246 (1978). 